\title{
Editorial
}

\section{COVID-19: an opportunity to research and publish about its impact on tourism and the environment}

Arcadio A. Cerda

Editor RIAT

Without a doubt, the pandemic derived from COVID-19 has had significant impacts not only on people's health and well-being, but also on tourism and the environment. In tourism, this has implied a significant drop in the economic activity of the sector, with the consequent impact on people's income and employment. There was a significant reduction in the movement of passengers and visits to places of recreation worldwide, with borders being closed both internally and externally in the different countries, further aggravating the socioeconomic situation of the countries. On the other hand, in environmental matters, in this pandemic period the lowest levels of $\mathrm{CO} 2$ air pollution have been registered worldwide, which has benefited many countries that have serious air quality problems with a high impact on people's health.

Given the above, there are important opportunities for research and publication in environmental and tourism issues related to COVID-19. Therefore, in the next issues of RIAT, priority will be given to articles related to the pandemic. We call on researchers to make efforts to measure the socio-economic impacts on tourism and the environment. 